\title{
Outcomes of pancreaticoduodenectomy in patients with obstructive jaundice with and without preoperative biliary drainage: a retrospective observational study
}

\author{
Suvit Sriussadaporn*, Sukanya Sriussadaporn, Rattaplee Pak-art, Kritaya Kritayakirana, \\ Supparerk Prichayudh, Pasurachate Samorn, Natawat Narueponjirakul
}

\begin{abstract}
Background: Preoperative biliary drainage (PBD) in patients with obstructive jaundice from periampullary neoplasms may reduce the untoward effects of biliary obstruction and subsequent postoperative complications. However, PBD is associated with bile contamination and increases infectious complications after pancreaticoduodenectomy (PD).

Objectives: To determine whether PBD is associated with more complications after PD.

Methods: Patients with obstructive jaundice from periampullary lesions who underwent PD from 2000 to 2015 at our institution were retrospectively enrolled. The cohort was divided into a group with PBD and a group without. PBD was performed using one of the following methods: endoprosthesis, percutaneous transhepatic biliary drainage, surgical biliary-enteric bypass, or T-tube choledochostomy. PDs were performed by the first author using uniform surgical techniques. Postoperative complications were recorded. Statistical analyses were conducted using an unpaired $t$, Fisher exact, or chi-squared tests as appropriate.

Results: There were 26 with PBD and 28 patients without. Patients in the 2 groups were similar in age, presenting serum bilirubin level, operative time, operative blood transfusion, and hospital stay. The group with PBD had longer duration of jaundice, more patients presenting with cholangitis, and more patients with carcinoma of the ampulla of Vater. The overall complications were higher in patients in the group with PBD than in the group without.

Conclusions: PBD was associated with more complications overall after PD. However, PBD was necessary and lifesaving in certain clinical situations and improved the condition of patients before they underwent PD. Routine PBD in patients with obstructive jaundice without definite indications is not recommended.
\end{abstract}

Keywords: cholangitis; digestive system surgical procedures; drainage; jaundice; Pancreaticoduodenectomy

Pancreaticoduodenectomy (PD) is an operative procedure for treatment of periampullary neoplasms. Obstructive jaundice is the most common presentation in these patients owing to obstruction of the distal common bile duct. The adverse effects of malignant obstructive jaundice have been well documented, i.e., hepatic dysfunction, coagulation disorder,

*Correspondence to: Suvit Sriussadaporn, Department of Surgery, Faculty of Medicine, Chulalongkorn University, Bangkok 10330, Thailand, e-mail: suvit.s@chula.ac.th

Department of Surgery, Faculty of Medicine, Chulalongkorn University, Bangkok 10330, Thailand

2 Open Access. ( 2018 Suvit Sriussadaporn et al., published by Sciendo. (c) BY-NC-ND This work is licensed under the Creative Commons Attribution NonCommercial-NoDerivatives 4.0 License. 
cholangitis, impaired cellular immunity, and renal dysfunction [1-5]. Therefore, surgery on these patients may be associated with increased complications, especially, in a complex procedure such as PD [6-8]. Preoperative biliary drainage (PBD) was introduced in these patients to decrease serum bilirubin level with expected reduction of postoperative complications. The advantages of PBD in terms of decreasing postoperative complications have been reported and its use is recommended by several investigators early after initial introduction of PBD [9-12]. However, the major drawback of PBD is a bile culture positive for bacteria, which may increase postoperative infectious complications [13-15]. Furthermore, the PBD techniques (i.e., percutaneous transhepatic biliary drainage or PTBD, endoscopic biliary stenting or endoprosthesis, surgical biliaryenteric bypass, or T-tube choledochostomy) may contribute to complications related to the procedure. All of these negative impacts on $\mathrm{PBD}$ have led to reconsideration of routine use of PBD in patients with obstructive jaundice. Several studies of effects of PBD on postoperative outcomes in patients with periampullary tumors included both palliative internal bypass in unresectable patients and PD in those who were considered resectable. Therefore, results are difficult to interpret owing to different operative procedures. Examining effects of PBD with only one surgical procedure such as PD only would contribute to more meaningful analyses. Until now, the majority of studies directly concentrated to PBD and outcomes after PD have come from Europe and North America [16-24]. The purpose of this study was to compare outcomes of patients who underwent PD with and without PBD at our institution, a large established tertiary teaching hospital in Thailand.

\section{Methods}

This was a retrospective observational study of a cohort of patients who had obstructive jaundice and underwent PD with and without PBD at Department of Surgery, General Surgery Division 2, King Chulalongkorn Memorial Hospital, Bangkok, Thailand from 2000 to 2015. The study protocol was approved by the Institutional Review Board (IRB) of the Faculty of Medicine, Chulalongkorn University (IRB No. 076/59, approval No. 313/2016) following the principles of the Declaration of Helsinki and its contemporary amendments. The inclusion criteria were patients who had obstructive jaundice and underwent $\mathrm{PD}$ with or without PBD. Patients were divided into 2 groups: group 1, with PBD and group 2, without PBD. PBD was performed using one of the following 4 methods: (1) endoscopic plastic or metallic stenting (endoprosthesis), (2) percutaneous transhepatic biliary drainage (PTBD), (3) biliary-enteric bypass, or (4)
T-tube choledochostomy. PD was uniformly performed by the first author in the same manner with external drainage of the pancreatic juice from the pancreatic remnant as previously described [25]. The reason for using external drainage to temporarily drain the pancreatic fluid out of the body was to prevent the pancreaticojejunostomy anastomotic leakage. When antrectomy was included in the operative procedure, the term "classical PD" was used. When the pylorus was preserved, the term "pylorus preserving PD or PPPD" was used. Postoperative complications were recorded and analyzed. Pancreatic fistula was defined as measurement of amylase level in the drainage fluid greater than 3 times the serum amylase on or after day 3 postoperatively [26]. Early delayed gastric emptying was defined as retained nasogastric tube of more than 10 days postoperatively or reintubation of the nasogastric tube after initial nasogastric tube removal and starting oral intake [27]. Results were expressed as range, median, and mean \pm SD. Statistical analyses comparing differences of variables and outcomes of patients who underwent PD with and without PBD were performed using a Fisher exact test, unpaired $t$ test, or chi-squared test as appropriate. $P<0.05$ was considered statistically significant.

\section{Results}

We entered data from 54 patients including 34 (63\%) men and $20(37 \%)$ women into the present study. Details of age, duration of jaundice before treatment, the presence of cholangitis, the serum bilirubin level at presentation, the operative procedure (classical PD or PPPD), the operative time, operative blood transfusion, and the length of hospital stay of all patients, and patients in groups 1 and 2 are shown in Tables 1 and 2. Patients in the 2 groups were similar in age, presenting serum bilirubin level, operative time, operative blood transfusion, and hospital stay. Duration of jaundice was longer in group 1 (with $\mathrm{PBD}, P=0.0035$ ).

In group 1, the PBD was performed with endoprosthesis in 17 patients $(65 \%)$, PTBD in 5 patients $(19 \%)$, biliary-enteric bypass in 3 patients $(12 \%)$, and T-tube choledochostomy in 1 patient (4\%). Of the 26 patients who had PBD, 11 (42\%) had cholangitis before $\mathrm{PBD}$. Of the 28 patients who underwent $\mathrm{PD}$ without PBD, no patient had cholangitis before the operation. Group 1 (with PBD) had significantly higher number of patients with cholangitis than in group $2(P<0.0001$; Table 2). Carcinoma of the head of the pancreas, carcinoma of the ampulla of Vater, and carcinoma of the distal common bile duct were the 3 leading pathological diagnoses. Carcinoma of the ampulla of Vater was more frequently found in group 1 than in group $2(P=0.029$; Table 3$)$. 
Table 1. Demographics and perioperative data of patients undergoing pancreaticoduodenectomy

\begin{tabular}{|c|c|c|c|c|c|c|c|c|c|c|}
\hline & \multicolumn{3}{|c|}{ All patients } & \multicolumn{3}{|c|}{ Group 1} & \multicolumn{3}{|c|}{ Group 2} & \multirow[t]{2}{*}{$P$} \\
\hline & Range & Mean & Median & Range & Mean & Median & Range & Mean & Median & \\
\hline Age (years) & $33-89$ & $62.9 \pm 12.7$ & 63.5 & $36-78$ & $59.7 \pm 11.0$ & 62 & $33-89$ & $65.9 \pm 13.5$ & 67 & NS \\
\hline $\begin{array}{l}\text { Presenting serum bilirubin } \\
(\mathrm{mg} \%)\end{array}$ & $5.5-52.7$ & $21.4 \pm 11.5$ & 20.6 & $8.7-52.0$ & $24.4 \pm 12.2$ & 21.2 & $5.5-52.7$ & $19.3 \pm 10.5$ & 20.3 & NS \\
\hline $\begin{array}{l}\text { Duration of jaundice } \\
\text { (days) }\end{array}$ & $7-120$ & $38.5 \pm 34.0$ & 30 & $7-120$ & $52.5 \pm 43.1$ & 42 & $8-60$ & $26.1 \pm 14.5$ & 30 & 0.0035 \\
\hline Operative time (minute) & $300-780$ & $420.6 \pm 82.8$ & 420 & $300-780$ & $423.5 \pm 96.8$ & 420 & $300-540$ & $417.9 \pm 67.1$ & 420 & NS \\
\hline $\begin{array}{l}\text { Operative blood transfusion } \\
\text { (unit) }\end{array}$ & $0-7$ & $2.7 \pm 1.7$ & 3 & $0-7$ & $2.8 \pm 2.0$ & 3 & $0-5$ & $2.6 \pm 1.4$ & 2.5 & NS \\
\hline Hospital stay (days) & $12-106$ & $28.9 \pm 17.8$ & 22.5 & $12-106$ & $31.8 \pm 23.3$ & 23.5 & $15-45$ & $26.1 \pm 9.5$ & 21 & NS \\
\hline
\end{tabular}

NS, not significant; PBD, Preoperative biliary drainage. Group 1 with PBD and group 2 without PBD.

Table 2. Cholangitis at presentation and operative procedure (classical PD or PPPD)

\begin{tabular}{lrrr}
\hline & Group 1 $(\mathbf{n = 2 6 )}$ & Group 2 $(\mathbf{n = 2 8 )}$ & $\boldsymbol{P}$ \\
\hline PPPD & 20 & 26 & NS \\
Classical PD & 6 & 2 & NS \\
Cholangitis & 11 & 0 & $<0.0001$ \\
No cholangitis & 15 & 28 & NS \\
\hline
\end{tabular}

Classical PD, classical pancreaticoduodenectomy; NS, not significant; PPPD, pylorus preserving pancreaticoduodenectomy; group 1 with PBD and group 2 without PBD.

Table 3. Pathological diagnosis of the periampullary lesions

\begin{tabular}{|c|c|c|c|c|}
\hline Pathological diagnosis & All patients & Group 1 & Group 2 & $P$ \\
\hline $\begin{array}{l}\text { Carcinoma of the head } \\
\text { of the pancreas }\end{array}$ & 23 & 10 & 13 & NS \\
\hline $\begin{array}{l}\text { Carcinoma of the ampulla } \\
\text { of Vater }\end{array}$ & 20 & 14 & & 0.029 \\
\hline $\begin{array}{l}\text { Carcinoma of the distal } \\
\text { common bile duct }\end{array}$ & 5 & 0 & 5 & NS \\
\hline Chronic pancreatitis & 2 & 0 & 2 & NS \\
\hline $\begin{array}{l}\text { Carcinoma of the } \\
\text { duodenum }\end{array}$ & 1 & 0 & 1 & NS \\
\hline Acute pancreatitis & 1 & 1 & 0 & NS \\
\hline $\begin{array}{l}\text { Sarcoma of the pancreatic } \\
\text { head }\end{array}$ & 1 & 0 & 1 & NS \\
\hline $\begin{array}{l}\text { Neuroendocrine tumor of } \\
\text { the pancreas }\end{array}$ & 1 & 1 & 0 & NS \\
\hline Total & 54 & 26 & 28 & \\
\hline
\end{tabular}

NS, not significant.
Table 4. Postoperative complications

\begin{tabular}{lrrr}
\hline Complication & $\begin{array}{r}\text { Group 1 } \\
(\mathbf{1 2} \text { in 26)* }\end{array}$ & $\begin{array}{r}\text { Group 2 } \\
(\mathbf{7} \text { in 28)* }\end{array}$ & $\boldsymbol{P}$ \\
\hline Wound infection & 3 & 3 & NS \\
Grade A pancreatic fistula & 5 & 1 & NS \\
Early delayed gastric emptying & 2 & 2 & NS \\
Intraabdominal bleeding & 2 & 1 & NS \\
Intraabdominal collection & 5 & 1 & NS \\
Congestive heart failure & 0 & 1 & NS \\
Overall complications & 17 & 9 & 0.03 \\
\hline
\end{tabular}

*Some patients had more than one complication.

Classical PD, classical pancreaticoduodenectomy; NS, not significant; $\mathrm{PBD}$, preoperative biliary drainage; $\mathrm{PD}$, pancreaticoduodenectomy; PPPD, pylorus preserving pancreaticoduodenectomy. Group 1 with PBD and group 2 without PBD.

Twelve patients in group $1(65.4 \%)$ had 17 complications, while 7 in group 2 (25\%) had 9 complications. Details of complications are shown in Table 4. There was no difference in occurrence of postoperative wound infection, pancreatic fistula, early delayed gastric emptying, intraabdominal bleeding, and intraabdominal collection between the 2 groups. However, group 1 (with PBD) had significantly higher overall complications than group $2(P=0.03)$.

\section{Discussion}

The present study demonstrated that patients with PBD had more complications overall after PD than patients with surgery alone. These findings are consistent with previous reports from 
Europe and North America [16, 20, 22, 23]. Although highly elevated serum bilirubin level has been shown to be associated with negative host-defense mechanisms with increased postoperative complications, the negative impact of PBD in terms of increased postoperative infectious complications and procedure-related complications should also be considered when PBD is contemplated. Currently, most investigators are in agreement that jaundiced patients may safely undergo PD without PBD and routine PBD in these patients is no longer recommended [28]. Although the duration of jaundice of patients with PBD in this study was significantly longer than those without PBD, the serum bilirubin levels at presentation were not different. Early surgery without PBD in our patients was successfully performed even in patients with serum bilirubin level as high as $52.7 \mathrm{mg} \%$. However; in our opinion, selective use of PBD may be necessary. Currently, it is generally accepted that PBD may be used in patients with one or more of the following indications: (1) cholangitis, (2) delayed surgery to improve conditions of patients, (3) delayed surgery to manage other more urgent conditions, and (4) delayed surgery for neoadjuvant therapy. Despite the disadvantages of PBD, i.e., bile contamination and complications related to the PBD procedures, the authors frequently experienced remarkable advantages to PBD. On several occasions, PBD was a lifesaving procedure in patients with obstructive jaundice presenting with cholangitis. In the PBD group, 11 (42\%) patients had cholangitis at presentation and these patients benefited from PBD to improve their conditions before undergoing PD. One patient with carcinoma of the ampulla of Vater in this study presented with deep jaundice. On preoperative evaluation, she also had significant coronary artery disease necessitating coronary artery bypass grafting $(\mathrm{CABG})$ and delayed $\mathrm{PD}$. She immediately received PBD (with an endoprosthesis) and uneventful CABG. One month later she underwent successful PD. She is alive and well at the time of preparing this manuscript, 8 years after PD. These examples emphasize the benefit of PBD in some special circumstances.

The shortcomings of the present study are its retrospective methodology, relatively small number of patients in each group, and 4 different methods of PBD rendering a less convincing interpretation of results. Endoscopic retrograde cholangiopancreatography (ERCP) with insertion of endoprosthesis was most commonly performed in our study (17 patients, $65 \%$ ), followed by PTBD (5 patients, $19 \%$ ), biliaryenteric bypass ( 3 patients, 12\%), and T-tube choledochostomy (1 patient, 4\%). ERCP with insertion of endoprosthesis is generally accepted as a procedure of choice when PBD is considered necessary [20, 22, 23, 28]. In our present study, PTBD was performed when insertion of endoprosthesis is unsuccessful.
For 4 patients who had surgical PBD, i.e., biliary-enteric bypass ( 3 patients) and T-tube choledochostomy (1 patient), all the procedures had been performed elsewhere before referring the patients to our institution for PD. Nevertheless, an obvious advantage of this study was the uniformity of the surgical techniques in both groups. All operations were performed by the first author using the same surgical techniques, which helped to lessen the confounding factors related to the various surgical techniques used by different surgeons as commonly seen in most reports. In our opinion, the consistency of surgical techniques is important when outcomes after PD are compared between the 2 groups of patients. Because PD is a complex and technically demanding surgical procedure; to our knowledge, this type of study is seldom published in Thailand and the South East Asian region.

\section{Conclusion}

We found that patients who had undergone PBD before PD had higher overall complications than those who had surgery alone. However, those in the PBD group had significantly longer duration of jaundice and more patients presented with cholangitis rendering PBD a necessary procedure to improve the condition of patients. The authors agree with many investigators that patients with obstructive jaundice may safely undergo PD without PBD if no definite indications for PBD exist.

Author contributions. All authors contributed substantially to the conception and design of the study. All authors analyzed and interpreted the data. Suvit S substantially drafted the manuscript. Sukanya S, RP, KK, SP, PS, and NN critically revised the manuscript. All authors approved the final version submitted and take responsibility for statements made in the published article.

Acknowledgments. The authors thank King Chulalongkorn Memorial Hospital and the Thai Red Cross Society for providing invaluable supports to all participating patients. We did not receive any specific grant for this research from any funding agency in the public, commercial, or not-for-profit sectors.

Conflict of interest statement. The authors have each completed and submitted an International Committee of Medical Journal Editors Uniform Disclosure Form for Potential Conflicts of Interest. None of the authors have any potential conflict of interest to disclose. 


\section{References}

[1] Gouma DJ, Coelho JC, Fisher JD, Schlegel JF, Li YF, Moody FG. Endotoxemia after relief of biliary obstruction by internal and external drainage in rats. Am J Surg. 1986; 151:476-9.

[2] Roughneen PT, Gouma DJ, Kulkarni AD, Fanslow WF, Rowlands BJ. Impaired specific cell-mediated immunity in experimental biliary obstruction and its reversibility by internal biliary drainage. J Surg Res. 1986; 41:113-25.

[3] Gouma DJ, Roughneen PT, Kumar S, Moody FG, Rowlands BJ. Changes in nutritional status associated with obstructive jaundice and biliary drainage in rats. Am J Clin Nutr. 1986; 44:362-9.

[4] Gouma DJ, Caelho JC, Schlegel JF, Li YF, Moody FG. The effect of preoperative internal and external biliary drainage on mortality of jaundiced rats. Arch Surg. 1987; 122:731-4.

[5] Bemelmans MH, Gouma DJ, Greve JW, Buurman WA. Effect of antitumour necrosis factor treatment on circulating tumour necrosis factor levels and mortality after surgery in jaundiced mice. Br J Surg. 1993; 80:1055-8.

[6] Pitt HA, Cameron JL, Postier RG, Gadacz TR. Factors affecting mortality in biliary tract surgery. Am J Surg. 1981; 141:66-72.

[7] Armstrong CP, Dixon JM, Taylor TV, Davies GC. Surgical experience of deeply jaundiced patients with bile duct obstruction. Br J Surg. 1984; 71:234-8.

[8] Greig JD, Krukowski ZH, Matheson NA. Surgical morbidity and mortality in one hundred and twenty-nine patients with obstructive jaundice. Br J Surg. 1988; 75:216-9.

[9] Takada T, Hanyu F, Kobayashi S, Uchida Y. Percutaneous transhepatic cholangial drainage: direct approach under fluoroscopic control. J Surg Oncol. 1976; 8:83-97.

[10] Nakayama T, Ikeda A, Okuda K. Percutaneous transhepatic drainage of the biliary tract: technique and results in 104 cases. Gastroenterology. 1978; 74:554-9.

[11] Denning DA, Ellison EC, Carey LC. Preoperative percutaneous transhepatic biliary decompression lowers operative morbidity in patients with obstructive jaundice. Am J Surg. 1981; 141:61-5.

[12] Gundry SR, Strodel WE, Knol JA, Eckhauser FE, Thompson NW. Efficacy of preoperative biliary tract decompression in patients with obstructive jaundice. Arch Surg. 1984; 119:703-8.

[13] Cortes A, Sauvanet A, Bert F, Janny S, Sockeel P, Kianmanesh R, et al. Effect of bile contamination on immediate outcomes after pancreaticoduodenectomy for tumor. J Am Coll Surg. 2006; 202:93-9.

[14] Sudo T, Murakami Y, Uemura K, Hayashidani Y, Hashimoto Y, Ohge $\mathrm{H}$, Sueda T. Specific antibiotic prophylaxis based on bile cultures is required to prevent postoperative infectious complications in pancreaticoduodenectomy patients who have undergone preoperative biliary drainage. World J Surg. 2007; 31:2230-5.

[15] Limongelli P, Pai M, Bansi D, Thiallinagram A, Tait P, Jackson J, et al. Correlation between preoperative biliary drainage, bile duct contamination, and postoperative outcomes for pancreatic surgery. Surgery. 2007; 142:313-8.
[16] Povoski SP, Karpeh MS, Conlon KC, Blumgart LH, Brennan MF. Association of preoperative biliary drainage with postoperative outcome following pancreaticoduodenectomy. Ann Surg. 1999; 230:131-42.

[17] Sohn TA, Yeo CJ, Cameron JL, Pitt HA, Lillemoe KD. Do preoperative biliary stents increase post pancreaticoduodenectomy complication? J Gastrointest Surg. 2000; 4:258-68.

[18] Sewnath ME, Birjmohun RS, Rauws EA, Huibregtse K, Obertop $\mathrm{H}$, Gouma DJ. The effect of preoperative biliary drainage on postoperative complications after pancreaticoduodenectomy. J Am Coll Surg. 2001; 192:726-34.

[19] Coates JM, Beal SH, Russo JE, Vanderveen KA, Chen SL, Bold RJ, Canter RJ. Negligible effect of selective preoperative biliary drainage on perioperative resuscitation, morbidity, and mortality in patients undergoing pancreaticoduodenectomy. Arch Surg. 2009; 144:841-7.

[20] Haapamäki C, Seppänen H, Udd M, Juuti A, Halttunen J, Kiviluoto T, et al. Preoperative biliary decompression preceding pancreaticoduodenectomy with plastic or self-expandable metallic stent. Scand J Surg. 2014; 104:79-85.

[21] Singhirunnusorn J, Roger L, Chopin-Laly X, Lepilliez V, Ponchon T, Adham M. Value of preoperative biliary drainage in a consecutive series of resectable periampullary lesions. From randomized studies to real medical practice. Langenbecks Arch Surg. 2013; 398:295-302.

[22] di Mola FF, Tavano F, Rago RR, De Bonis A, Valvano MR, Andriulli A, di Sebastiano P. Influence of preoperative biliary drainage on surgical outcome after pancreaticoduodenectomy: single centre experience. Langenbecks Arch Surg. 2014; 399:649-57.

[23] Arkadopoulos N, Kyriazi MA, Papanikolaou IS, Vasiliou P, Theodoraki K, Lappas C, et al. Preoperative biliary drainage of severely jaundiced patients increases morbidity of pancreaticoduodenectomy: results of a case-control study. World J Surg. 2014; 38:2967-72.

[24] Sauvanet A, Boher JM, Paye F, Bachellier P, Sa Cuhna A, Le Treut YP, et al. Severe jaundice increases early severe morbidity and decreases long-term survival after pancreaticoduodenectomy for pancreatic adenocarcinoma. J Am Coll Surg. 2015; 221:380-9.

[25] Sriussadaporn S, Pak-Art R, Sriussadaporn S, Kritayakirana K, Prichayudh S. Pancreaticoduodenectomy with external drainage of the pancreatic remnant. Asian J Surg. 2008; 31:167-73.

[26] Bassi C, Dervenis C, Butturini G, Fingerhut A, Yeo C, Izbicki J, et al. Postoperative pancreatic fistula: an international study group (ISGPF) definition. Surgery. 2005; 138:8-13.

[27] Sriussadaporn S, Prichayudh S, Sriussadaporn S, Kritayakirana K, Pak-art R. Pylorus preserving pancreaticoduodenectomy with low incidence of early delayed gastric emptying. J Med Assoc Thai. 2007; 90:82-8.

[28] van der Gaag NA, Rauws EA, van Eijck CH, Bruno MJ, van der Harst E, Kubben FJ, et al. Preoperative biliary drainage for cancer of the head of the pancreas. N Engl J Med. 2010; 362:129-37. 